Prismatika: Jurnal Pendidikan dan Riset Matematika Vol. 3 No. 1 (2020)

p-ISSN: 2654-6140, e-ISSN: 2656-4181

http://ejurnal.budiutomomalang.ac.id/index.php/prismatika

\title{
PENINGKATAN HASIL BELAJAR MATERI PECAHAN DENGAN MODEL PEMBELAJARAN PAKEM SISWA SEKOLAH DASAR
}

\author{
Asri Putri Anugraini ${ }^{1}$, Anik Kurniawati ${ }^{2}$ \\ IKIP Budi Utomo Malang1,2 \\ asriputrianugraini89@gmail.com ${ }^{1}$, anikkurnia2016@gmail.com ${ }^{2}$
}

\begin{abstract}
Abstrak
Keberhasilan belajar tercipta jika siswa mau bersungguh-sungguh dalam belajar, aktif, dan kreatif dalam memecahkan masalah matematika. Fokus penelitian ini mengutamakan proses belajar dengan perbaikan sistem belajar matematika pada materi pecahan (perkalian pecahan) dengan pendekatan PAKEM (Pembelajaran Aktif, Kreatif, Efektif, dan Menyenangkan). Perbaikan sistem belajar di kelas dapat menjadikan keberhasilan dalam meningkatan kemampuan siswa secara aktif, mandiri, dan kreatif. Sehingga peneliti memilki komitmen dalam mengupayakan perbaikan dan peningkatan kualitas pembelajaran. Penelitian yang digunakan oleh peneliti adalah PTK. Subjek penelitian tindakan kelas ini adalah siswa kelas V SD Mangunrejo 2 yang berjumlah 20 siswa. Hasil penelitin siklus I dan siklus II mengalami kenaikan dari 74,90\% naik menjadi 80,20\%.
\end{abstract}

Kata kunci: pecahan, PAKEM, hasil belajar

\begin{abstract}
Learning success is created if students want to be serious in learning, active, creative in solving math problems. The focus of the study was the learning process by improving the mathematics learning system on fractions (multiplication of fractions) with the PAKEM approach. By improving the learning system in the classroom, it can lead to success in increasing students' abilities actively, independently, and creatively. So that researchers commit to strive for improvement of the quality of learning. The research used by researchers was Classroom Action Research (PTK). The subjects of this classroom action research were students of grade V SD Mangunrejo 2, totaling 20 students. The results of the research cycle I and cycle II increased from $74,90 \%$ to $80,20 \%$.
\end{abstract}

Keywords: fraction, PAKEM, learning outcomes

\section{PENDAHULUAN}

Pendidikan bertujuan untuk mencerdaskan kehidupan bangsa. Belajar matematika dapat menjadikan siswa menjadi aktif, kreatif, teliti, berpikir kritis. Hal ini sepadan dengan pendapat Ibrahim \& Suparni (2012) bahwa 
Asri Putri Anugraini, Anik Kurniawati

Peningkatan Hasil Belajar Materi Pecahan dengan Model Pembelajaran PAKEM Siswa Sekolah

Dasar

matematika dapat dijadikan bekal bagi siswa agar mempunyai kemampuan berpikir yang bagus.

Pembelajaran matematika merupakan kegiatan belajar yang mempunyai rencana terstuktur melibatkan pikiran dan aktivitas dalam pengembangan kemampuan pemecahan masalah serta penyampaian informasi gagasan (Wandini \& Banurea, 2019). Hasil pengamatan awal sebelum penelitian siswa dalam belajar matematika kelas V SD Negeri 02 Mangurejo siswa mengatakan kesulitan memahami karena terlalu banyak rumus dan materi sulit dipahami. Penyebab minimnya nilai siswa kelas V di SDN 2 Mangunrejo Kepanjen adalah kegiatan belajar yang kurang menarik, kurang adanya sentuhan media pembelajaran, guru lebih banyak menjelaskan dan jarang sekali menggunakan benda konkrit sebagai alat untuk membantu proses pembelajaran. Kemudian guru juga jarang sekali menggunakan model pembelajaran matematika. Berdasarkan kasus-kasus yang dipaparkan, berdampak pada siswa karena kurang termotivasinya, kurang ada kesempatan berpikir, takut bertanya, takut memberi komentar, serta menjadikan siswa merasa jenuh dan mudah bosan. Hal ini dapat diketahui dai kondisi siswa di kelas yang kurang aktif, siswa terlalu senang dengan bermain dari pada belajar, sehingga pembelajaran berlangsung kurang maksimal.

Pendekatan untuk siswa di SD Negeri 2 Mangunrejo yang bisa mengubah siswa menjadi semangat belajar dan bisa mengaktifkan kembali minat siswa yaitu dengan pendekatan PAKEM (Pembelajaran Aktif, Kreatif, Efektif, dan Menyenangkan). Pendekatan ini bertujuan menumbuhkan semangat siswa, membangkitkan cara berpikir siswa dengan kreatif sehingga pembelajaran lebih bermakna dan tidak membosankan. Budimansyah, Suparlan, \& Meirawan (2009) mengatakan bahwa sebaiknya pada pendekatan PAKEM sebaiknya membuat kondisi pembelajaran menjadi menggembirakan sehingga siswa aktif bertanya dan berpendapat mengungkapkan gagasan sendiri. Pendapat yang sama dikemukakan oleh Endang (2010) bahwa Model PAKEM mengajak siswa terlibat dalam berpartisipasi secara aktif selama proses pembelajaran belajar berdasarkan hasil pengalamannya sendiri, bukan ditransfer pengetahuan dari guru. Novianingsih (2016) juga mengatakan bahwa pendekatan PAKEM dapat meningkatkan motivasi belajar siswa. Begitu pula Sutomo (2017) menyatakan bahwa pembelajaran PAKEM dapat meningkatkan motivasi dan hasil belajar.

Pembelajaran PAKEM dapat membuat siswa menjadi lebih aktif, mandiri dan kreatif. Sebagian besar siswa sulit memahami materi pecahan. Seperti yang dikatakan oleh Bentley \& Bosse (2018) bahwa siswa sekolah dasar perlu perjuangan dalam memahami konsep pecahan. (Kolar, Cadez, \& Vula, 2018) juga mengatakan bahwa pengetahuan siswa tentang pecahan 
sangat penting karena pecahan menyajikan konsep yang digunakan dalam belajar matematika selanjutnya. Selain itu, pecahan penting dalam pekerjaan sehai-hari (Bruce and Ross dalam Bruce, Chang, \& Flynn, 2013).

Pecahan dapat diartikan sebagai bagian dari sesuatu yang utuh. Bilangan pecahan merupakan bagian dari sesuatu yang utuh. Pecahan dapat menggunakan gambar ilustrasi yang ditandai dengan arsiran. Bagian yang diarsir disebut pembilang dan yang utuh dianggap sebagai satuan dan disebut penyebut (Heruman, 2008).

Materi pecahan dapat lebih dipahami oleh siswa dengan cara diberi pemecahan masalah sebagai awal dari uji coba penelitian. Berikut pemberian soal pemecahan masalah untuk siswa: Adika memiliki selembar kertas berwarna atau origami. Kertas origami dipotong menjadi dua bagian yang sama dengan Aliya. Dengan demikian Aliya mendapat $\frac{1}{2}$ bagian

Peragaan kertas dalam pengenalan pecahan $\frac{1}{2}$ dapat dilakukan seperti gambar berikut.

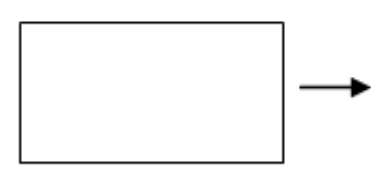

1

Kertas utuh

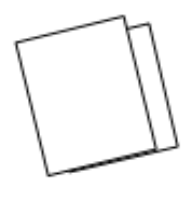

Kertas dilipat menjadi 2 bagian
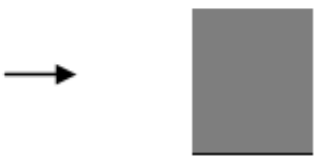

$\frac{1}{2}$

Kertas yang sudah dibagi menjadi 2 bagian

\section{Gambar 1. Peragaan Pecahan dengan Kertas}

Jadi, Aliya mendapat bagian $\frac{1}{2}$.

Penelitian ini berfokus pada operasi perkalian pecahan. Berikut mengenai operasi perkalian pecahan campuran.

"Untuk mengisi sebuah kaleng, 5 orang anak masing-masing menuangkan $\frac{1}{2}$ liter air. Berapa liter air isi kaleng itu?"

Penyelesaian:

Isi kaleng itu $=\frac{1}{2}+\frac{1}{2}+\frac{1}{2}+\frac{1}{2}+\frac{1}{2}$, atau $5 \times \frac{1}{2}=\frac{5 \times 1}{2}=\frac{5}{2}=2 \frac{1}{2}$

Jadi, isi kaleng itu $2 \frac{1}{2}$ “ 
Asri Putri Anugraini, Anik Kurniawati

Peningkatan Hasil Belajar Materi Pecahan dengan Model Pembelajaran PAKEM Siswa Sekolah Dasar

Proses belajar siswa sekolah dasar hendaknya disesuaikan dengan tahap perkembangan siswanya. Siswa perlu konsentrasi membaca dan memperhatikan apa yang disampaikan guru. Seorang siswa dikatakan memahami sesuatu jika siswa mampu menyampaikan uraian yang lebih rinci dan jelas menggunakan bahasa sendiri. Piaget (dalam Budiningsih, 2012) mengatakan bahwa tahap perkembangan kognitif adalah semua tentang belajar. Perkembangan meliputi kemampuan anak sekolah pada masalah matematika, keberanian anak usia sekolah dalam mengajukan pertanyaan setelah mereka membaca sesuatu.

Hasil penyelidikan awal di sekolah pada matematika di kelas $\mathrm{V}$ ditemukan kasus seperti siswa kurang konsentrasi pada materi yang disampaikan guru, siswa kurang terlibat dalam belajar, siswa asik sendiri bermain saat belajar, metode yang digunakan kurang tepat, dan hasil belajar siswa matematika siswa kurang memuaskan. Diketahui hasil siswa ujian semeter 1 menunjukan nilai rata-rata yaitu 53,3. Hasil tersebut belum dinyatakan tuntas sesuai KBM matematika karena standar nilai pada mata pelajaran matematika yaitu 70,0.

Model pembelajaran PAKEM merupakan metode tepat untuk mengatasi masalah belajar siswa pda pembelajaran matematika di kelas V SD Negeri 2 Mangunrejo. Model pembelajaran PAKEM ini sesuai dengan keadaan siswa SD pada tahap operasional konkret. Model pembelajaran PAKEM ini bisa diberikan di kelas V SD Negeri 2 Mangunrejo pada pelajaran matematika karena model PAKEM ini dibuat untuk mingkatkan belajar siswa dan mengaktifkan siswa pada pembelajaran matematika dengan media konkret (dalam penelitian ini menggunakan kertas), agar siswa aktif, terampil, dan kreatif serta bebas menggunakan media sebagai alat belajar.

\section{METODE PENELITIAN}

Penelitian tindakan kelas difokuskan dapat meningkatkan proses belajar siswa dan hasil belajar siswa di kelas yang dilakukan dengan dua siklus. Menurut Jasa Menurut Rapoport dan Hopkins (Kunandar, 2011), penelitian tindakan kelas merupakan penelitian yang membantu siswa mengatasi masalah. (Arikunto, 2009) mengatakan bahwa penelitian tindakan kelas merupakan suatu pencermatan dan tindakan dalam kegiatan pembelajaran. Sehingga PTK sangat praktis dan cocok bagi guru supaya menjadi peka tanggap terhadap dinamika pembelajaran di kelasnya.

Materi yang akan disampaikan ke siswa dalam penelitian pecahan dengan model PAKEM yaitu:

1. Mengalikan Pecahan biasa dengan Pecahan Biasa 
Asri Putri Anugraini, Anik Kurniawati

Peningkatan Hasil Belajar Materi Pecahan dengan Model Pembelajaran PAKEM Siswa Sekolah

Dasar

Menurut Masykur, dkk (2010), aturannya dalam mengalikan pecahan

$$
\frac{\text { pembilang }}{\text { penyebut }} \times \frac{\text { pembilang }}{\text { penyebut }}=\frac{\text { pembilang } \times \text { pembilang }}{\text { penyebut }}
$$

2. Mengalikan Bilangan Asli dengan Pecahan Biasa

$$
\text { bilangan asli } \times \frac{\text { pembilang }}{\text { penyebut }}=\frac{\text { bilangan asli } \times \text { pembilang }}{\text { penyebut }}
$$

3. Mengalikan Pecahan Campuran dengan Pecahan Campuran

4. Mengalikan Bilangan Asli dengan Pecahan Campuran

Siswa kelas V Sekolah Dasar Negeri 2 Mangunrejo Kepanjen menjadi subjek utama dalam penelitian ini dengan jumlah siswa sebanyak 24 anak. Uji coba ini difokuskan terkait proses belajar dan hasil belajar matematika pada materi pecahan pokok bahasan perkalian pecahan melalui model pembelajaran PAKEM.

Model Kemmis \& Mc Taggart ada empat langkah yang dipakai dalam PTK meliputi: perencanaan, tindakan, observasi, dan refleksi. Langkahlangkah ini saling berkaitan sehingga perlu disiapkan seperangkat rencana tindakan untuk memulai tahap tindakan. Penelitian tindakan kelas dimulai dari studi pendahuluan kemudian merumuskan masalah (Arikunto, 2009). Pengumpulan data yang dipakai penelitian berupa wawancara, angket, observasi, tes, dan dokumentasi.

\section{HASIL DAN PEMBAHASAN}

Penelitian di SD Negeri 2 Mangunrejo menggunakan PAKEM. Penelitian ini dilakukan 2 siklus dimana setiap siklus terdiri dari tiga pertemuan. Penelitian diawali wawancara kepada guru kelas. Sebelum penelitian dilaksanakan, peneliti melihat hasil UTS siswa yakni nilai rata- ratanya 51,0. Maka belum dinyatakan tuntas sesuai KKM yaitu 70.

Siklus pertama, peneliti mempersiapkan perangkat dan bahan ajar yang akan digunakan untuk penelitian. SKBM yang digunakan untuk materi pecahan yaitu mengalikan dan membagi berbagai bentuk pecahan. Siklus pertama dilaksanakan sebanyak tiga kali pertemuan. Proses pelaksaanan siklus I, guru sebagai pelaksana dan peneliti sebagai pengamat.

Guru dan peneliti memperhatikan gerak gerik siswa agar siswa jujur, percaya diri saat menyelesaikan soal, sehingga tidak terjadi kecurangan siswa ketika mengerjakan soal. Soal yang diberikan siswa berjumlah 10 soal dalam bentuk esai berisi tentang materi pada pertemuan 1 dan 2. Alasan peneliti memberi soal esai adalah agar siswa lebih berpikir kreatif dalam penyelesaian.

Siklus I ditemukan kasus beberapa siswa tidak fokus karena masih ada yang menoleh ke kanan dan ke kiri, melirik jawaban teman, siswa kurang aktif 
Asri Putri Anugraini, Anik Kurniawati

Peningkatan Hasil Belajar Materi Pecahan dengan Model Pembelajaran PAKEM Siswa Sekolah

Dasar

dalam berpendapat, beberapa siswa menjawab tidak mengikuti petunjuk yang diberikan oleh guru, siswa kurang teliti dalam menghitung dan meletakan angka. Pertemuan pertama dan kedua, kegiatan siswa adalah memahami materi dengan pemecahan masalah. Hasil dari siklus pertama diambil dari latihan mengerjakan soal LKS di pertemuan ketiga. Hasil di siklus pertama menunjukkan hasil siswa rata-ratanya 73,50 . Temuan yang terjadi di siklus pertama siswa ada yang mencontek, tidak percaya diri dalam menjawab, terburu-buru menjawab soal, kuranng konsentrasi.

Siklus kedua mengalami perubahan dibandingkan siklus pertama siswa dipandu untuk fokus pada pekerjaan masing-masing, pada tempat duduk siswa diberi jarak agar tidak saling berdempetan yang menimbulkan kecurangan, serta nilai di bawah KBM maka perlu dilanjutkan perbaikan ke siklus II. Perbaikan di siklus II yaitu meroling tempat duduk siswa dan memberi jarak tempat duduk dan menegaskan siswa tidak lagi bermain dengan teman sebangku dan guru diminta tidak terlalu cepat untuk menjelaskan dan memberi petunjuk kepada siswa. Siklus kedua terjadi peningkatan yaitu pada siklus I rata-ratanya 73,50 dan pada siklus II rataratanya menjadi 83,61. Sesuai paparan siklus I dan siklus II disimpulkan bahwa penelitian mengalami peningkatan. Berdasarkan penelitian yang dilakukan selama dua siklus dapat disimpulkan bahwa pembelajaran PAKEM bisa menjadikan keberhasilan dalam meningkatan kemampuan siswa secara aktif, mandiri, dan kreatif. Hal ini sejalan dengan hasil penelitian Lumbu \& Budiarti (2015) yang menyimpulkan bahwa pembelajaran PAKEM dapat meningkatkan aktivitas dan hasil belajar mahasiswa. Aslinda (2017) juga mengatakan bahwa pembelajaran PAKEM dapat meningkatkan hasil belajar siswa.

Berdasarkan pembelajaan PAKEM yang telah dilaksanakan pada penelitian ini, guru memberikan dorongan dengan cara memberi semangat positif dan meyakinkan, dengan demikian siswa akan menjadi lebih terbuka dalam belajar matematika, sehingga pada akhirnya akan merasa lebih percaya diri dan termotivasi.

\section{KESIMPULAN DAN SARAN}

Berdasarkan penelitian yang sudah dilaksanakan di SD Negeri 2 Mangunrejo pada mata pelajaran matematika materi perkalian pecahan menunjukan peningkatan hasil belajar. Hasil presentasi naik sebesar 5,92\%. Di siklus I mencapai 73,50\%, naik menjadi $81,61 \%$ pada siklus II. Pengamatan pada guru juga mengalami peningkatan, yaitu siklus I presentase $74,90 \%$ naik menjadi $80,20 \%$ pada siklus II. Sehingga penelitian ini mengalami peningkatan 
Asri Putri Anugraini, Anik Kurniawati

Peningkatan Hasil Belajar Materi Pecahan dengan Model Pembelajaran PAKEM Siswa Sekolah

Dasar

sesuai target penelitian. Saran bagi para guru, sebaiknya pemilihan model pembelajaran disesuaikan dengan keaadan siswa. Berikan ruang kepada siswa dalam mengeksplor kemampuan belajar di kelas serta motivasi siswa dalam setiap belajarnya.

\section{DAFTAR RUJUKAN}

Arikunto, S. (2009). Penelitian Tindakan Kelas. Jakarta: Bumi Aksara.

Aslinda. (2017). Penerapan Model Pembelajaran PAKEM dalam Meningkatakan Hasil Belajar pada Materi Sepak Bola Siswa Kelas IV B SD Negeri 013 Mekarsari. Jurnal Primary Program Studi Pendidikan Guru Sekolah Dasar Fakultas Keguruan Dan Ilmu Pendidikan Universitas Riau, 6(2), 472-481.

Bentley, B., \& Bosse, M. J. B. (2018). College Students' Understanding of Fraction Operation. Internatonal Electronic Journal of Mathematics Education, 13(3), 233-247.

Bruce, C., Chang, D., \& Flynn, T. (2013). Foundations to Learning and Teaching Fractions: Addition and Subtraction. Ontario Ministry of Education.

Budimansyah, D., Suparlan, \& Meirawan, D. (2009). PAKEM Pembelajaran Aktif, Efektif, Kreatif, dan Menyenangkan. Bandung: Genesindo.

Budiningsih, C. A. (2012). Belajar dan Pembelajaran. Jakarta: Rineka Cipta.

Endang, M. (2010). Pembelajaran Aktif, Kreatif, Inovatif, Efektif dan Menyenagkan (PAIKEM). Depdiknas.

Heruman. (2008). Model Pembelajaran Matematika Di Sekolah Dasar. Bandung: Remaja Rosdakarya.

Ibrahim, \& Suparni. (2012). Pembelajaran Matematika dan Aplikasinya. Yogyakarta: SUKA-Press UIN Sunan Kalijaga.

Kolar, V. M., Cadez, T. H., \& Vula, E. (2018). Primary Teacher Students' Understanding of Fraction Representational Knowledge in Slovenia and Kosovo. CEPS Jourrnal, 8(2), 71-96.

Kunandar. (2011). Langkah Mudah Penelitian Tindakan Kelas. Jakarta: PT. Rajawali Pers.

Lumbu, A., \& Budiarti, I. S. (2015). Peningkatan Hasil Belajar Menggunakan PAKEM dengan Metode Diskusi pada Pembelajaran Fisika Dasarr Pokok Bahasan Mekanika. Jurnal Pendidikan Fisika Dan Keilmuan (JPFK), 1(1), 23-28.

Masykur, A. dkk. (2010). Pintar Matematika Kelas 5 Sekolah Dasar Semester Kedua. Bogor: Yudhistira.

Novianingsih, H. (2016). Pendekatan Pembelajaran Aktif, Kreatif, Efektif, dan Menyenangkan dalam Pembelajaran Matematika Sekolah Dasar. Jurnal 
Pendidikan Guru Sekolah Dasar, 1(1), 1-11.

Sutomo. (2017). Pembelajaran Aktif, Kreatif, Efektif, dan Menyenangkan (PAKEM) dengan Metode Tim Kuis untuk Meningkatkan Motivasi dan Hasil Belajar Siswa Kelas X KKY 1 Materi Menyiapkan Proses Konstruksi Kayu pada SMK Negeri 1 Wonoasri Semester 2 Tahun Pelajaran 2016/201. El-Wasathiya: Jurnal Studi Agama, 5(2), 191-226. Wandini, R. R., \& Banurea, O. K. (2019). Pembelajaran Matematika untuk Calon Guru MI/SD. Medan: Widya Puspita. 